\title{
The Contribution of Emotional Intelligence and Achievement Motivation on Psychological Well-Being
}

\author{
Maryam Taiefeh Ghahremani ${ }^{1} \&$ Zohreh Ostovar $^{2}$ \\ ${ }^{1}$ Department of Psychology, Shahr-e-Qhods branch, Islamic Azad University, Tehran, Iran \\ ${ }^{2}$ Ph.D. Faculty Member of Rodehen Branch, Islamic Azad University, Tehran, Iran \\ Correspondence: Zohreh Ostovar, Ph.D. Faculty member of Rodehen branch, Islamic Azad University, Tehran, \\ Iran. Tel: 98-912-407-2874. E-mail: z_ostovar@yahoo.com
}

\author{
Received: October 22, 2016 Accepted: December 12, 2016 Online Published: January 25, 2017 \\ doi:10.5539/gjhs.v9n3p88 \\ URL: http://dx.doi.org/10.5539/gjhs.v9n3p88
}

\begin{abstract}
The purpose of this study was contribution of Emotional intelligence and achievement motivation on psychological well-being of students in the Shahr-e-Qods University. The statistical population of this study included all the students of University from 2015 to 2016. A sample of 200 students has been selected through cluster sampling. These students responded to a set of questionnaires included emotional intelligence (EI), achievement motivation, and psychological well-being. Hierarchical regression analyses conducted for each dependent variable showed that emotional intelligence and achievement motivation could be considered as important indicators of psychological well-being $(\mathrm{p}<0.01)$. The results indicated that achievement motivation can predict psychological well-being, and among emotional intelligence components, self-control and self-awareness can predict psychological well-being. As the results indicated, growth and promotion of the emotional intelligence can be considered as methods for improving students' psychological well-being. This can be promoted and revolted through a rich Educational Environment, so it is recommended to teach emotional intelligence skills to students with low psychological well-being through training workshops.
\end{abstract}

Keywords: emotional intelligence, achievement motivation, psychological well-being

\section{Introduction}

In traditional psychology, the category of why people experience destructive moods such as depression and anxiety is studied instead of examining what factors lead to positive moods such as happiness and hope in people. But recently, positive psychology studies how to help people achieve physical and psychological well-being, in the way that psychologists are guided towards examining more positive aspects of life. According to various studies on the effectiveness of interventions based on positive therapy (Danner, Snowden \& Friesen, 2001), identification and promotion of positive emotions and improvement of psychological well-being as a protective wall prevent depression, anxiety, chronic injuries and life stresses in people (Khodayari Fard, 2013).

When speaking of psychological health, positive aspects of performance such as positive affection, purpose in life, and social cooperation are considered (Keyes, 2007: qtd by Rahiminejad). In fact, well-being refers to individuals' feeling and thinking about life which is divided into two parts: A. emotional well-being which refers to pleasant and positive emotions (happiness) and the absence of unpleasant emotions (depression). B. cognitive well-being which refers to general cognitive assessments of life such as life satisfaction, as well as satisfaction of specific areas in life such as job or marital satisfaction (Diener, suh, Lucas, \& Smith, 1999). Access to psychological well-being requires understanding the challenges of life. Therefore, addressing these factors has led extensive collection of literature reviews in the 1950s and 1960s to analyze life challenges and major problems (Ryff \& Keyes, 2002). Some categories can be mentioned as factors affecting psychological well-being which are as follows: feeling of life satisfaction, happiness, spirituality, optimism, meaningfulness, self-accountability, personal growth and development, autonomy, purpose of life, and positive relations with others.

One of the concepts of intelligence is emotional intelligence which is remembered as the newest concept in understanding the relationship between reason and emotion and as well as a trigger of a great revolution in the field of mental health promotion (Tee, 2011). According to, (Mayer \& Salovey, 1997), emotional intelligence refers to a 
collection of personal capabilities in perception, management and proper planning of emotions. In some cases, it acts as coping strategy and solves the problems optimally by management of life stresses (Danesh, 2012). Regarding emotional intelligence, studies have shown that emotional intelligence is an effective and determining factor on outcomes of real life such as academic success in school, success in business and interpersonal relationships and generally in health-related functioning and high emotional intelligence is correlated with greater emotional and psychological health (Ciarrocchi et al., 2002). Emotional intelligence is actually related to emotional skills for proper understanding and expressing emotions, aligning feelings with the cognitive processes, understanding feelings and their functions in different situations and finally, controlling and managing emotions (Carmeli, 2003). Emotional intelligence, a skill in controlling one's emotions, is in the way that helps individual to achieve long-term happiness (Goleman, 1995, qtd by Shobairi, 2014). According to a research with a sample of 282 young people reported by (Mavroveli \& Petrides, 2007), relationship between emotional intelligence and psychological well-being was studied and the results showed that there is a positive relationship between these two variables and people who are in touch with their emotions and are able to order them, they suffer from less depression and physical problems and they are less vulnerable to the risk of psychological disorders. (Olson, 2008) has studied the relationship between emotional intelligence, self-esteem, well-being and academic achievement in a research. The findings show that emotional intelligence is better predicator of academic achievement than the self-esteem and well-being.

Achievement motivation is also the base for reaching success and all desires in life (Settlemyer, 2010). Achievement motivation is a mode of personality learning which leads people to try for success, gratification, and for higher personal standards (Wigfield \& Eccles, 2002). In fact, motivation is defined as a factor that initiates, guides, and maintains behavior. Achievement motivation is a comprehensive approach which evaluates its own performance based on the highest standards and makes an attempt to reach a successful performance accompanied by a pleasure. David McClelland believes that achievement motivation can be defined according to two concepts of competitiveness and a sense of superiority. Achievement motivation means needing to progress, overcoming obstacles, desiring for superiority, and maintaining high level standards (Karimi, 2005). Achievement motivation includes following factors: great desires, strong impetus for moving upwards, long resistance when facing with problems of moderate difficulty, desire to try again to perform incomplete assignments, dynamic perception of time, and fore sighting (Hermans, 1970). In a study titled "social background, achievement motivation, optimism, and psychological health", (Cassidy, 2000) concluded that family background such as socioeconomic status, family size and parental job is considered as a predicator of psychological health, achievement motivation, and optimism and achievement motivation plays the role of a mediator between family background and psychological health. According to what was mentioned, the purpose of this study was contribution of Emotional intelligence and achievement motivation on psychological well-being.

\section{Research Methodology}

This study is a descriptive and correlational research. The statistical population of this study included all of the students in Shahr-e-Qods University from 2015 to 1016. To obtain an appropriate sample, cluster sampling was used to gather information, a sample of 200 students has been selected.

\subsection{Ryff's Psychological Well-being Test}

This test with 84 questions was created by Carol Ryff at the University of Wisconsin in 1989. It was conducted on a group of 1108 people with 25 years of age and over. The subjects answer to questions based on the six point Likert scale from strongly disagree to strongly agree. Cronbach's coefficient alpha was reported 0.91 . The internal consistency coefficient of this questionnaire was calculated for each subscale as follows:

Autonomy (0.75), environmental mastery (0.75), personal growth (0.61), positive relationships with others $(0.71)$, having purpose in life (0.72), and self-acceptance (0.78) (qtd by Yahyazadeh, 2005).

\subsection{Cyberia Shrink's Emotional Intelligence Test}

This test with 33 questions was created by Cyberia Shrink in 1996; the test measures 5 components of emotional intelligence. Each subject receives 6 separate scores. Answers have been categorized according to Likert scale and Cronbach's alpha coefficient for reliability is reported $85 \%$. When examining the validity of this test, the correlation among the test scores of students at Tehran University was studied on a sample of 30 people. According to the information obtained $(\mathrm{r}=0.63),(\mathrm{p}=0.01)$, the internal correlation coefficient of students' scores is statistically significant (Mansouri, 2001). 


\subsection{Hermans' Achievement Motivation Test (A.M.T)}

Achievement motivation test with 29 questions was created by Hermans in 1970 . The final questionnaire was made only on the basis of 9 features. The standardization of achievement motivation test was conducted by Namdar on a sample group of 1073 people. Cronbach's alpha coefficient for reliability was reported $84 \%$. To calculate the validity of the test, the correlation coefficient ranges from 0.30 to 0.57 according to the questions order and the significant level is 0.01 (Namdar, 2003).

\subsection{Methods}

The sample was selected after necessary coordination. Then, the students were justified on how to complete the questionnaires and they were completed.

\section{Results}

Table 1. The correlation matrix of variables

\begin{tabular}{|c|c|c|c|c|c|c|c|}
\hline & 1 & 2 & 3 & 4 & 5 & 6 & 7 \\
\hline 1. Achievement Motivation & - & & & & & & \\
\hline 2.Emotional Intelligence -self- motivation & $0.300^{* *}$ & - & & & & & \\
\hline 3. Emotional Intelligence -self-awareness & $0.407 * *$ & $0.626^{* *}$ & - & & & & \\
\hline 4. Emotional Intelligence - self-control & $0.279^{* *}$ & $0.666^{* *}$ & $0.574 * *$ & - & & & \\
\hline 5. Emotional Intelligence - Social consciousness & $0.288^{* *}$ & $0.571^{* *}$ & $0.529 * *$ & $0.480^{* *}$ & - & & \\
\hline 6.Emotional Intelligence - social skills & 0.134 & $0.334 * *$ & $0.247 * *$ & $0.318^{* *}$ & $0.443 * *$ & - & \\
\hline 7. psychological well-being & $0.524 * *$ & $0.537 * *$ & $0.656^{* *}$ & $0.570 * *$ & $0.456^{* *}$ & $0.243 * *$ & - \\
\hline
\end{tabular}

Table 1 indicating the correlation coefficients shows dimensions of emotional intelligence, achievement motivation and psychological well-being. According to this table, all factors of emotional intelligence was correlated with psychological well-being with the significant level of 0.01 , and achievement motivation was also positively correlated with psychological well-being with the significant level of 0.01 . Hierarchical multivariate regression-based analysis was used to test the research hypothesis. In the way that the variable of achievement motivation and dimensions of emotional intelligence were entered into the predictive equation of psychological well-being as predictor variables respectively in the first and second steps. The analysis results are shown in table 2. The investigation of squared multiple correlation indicated that multiple correlation coefficient $\left(\underline{\mathrm{R}^{2}}\right)$ was equal to 0.267 . It reveals that achievement motivation explains the $26.7 \%$ of the psychological well-being variance. The investigation of regression coefficient showed that achievement motivation $(\beta=0.268, p<0.01)$ can positively predict psychological well-being with the significant level of 0.01 .

Table 2. Hierarchical multiple regression in predicting psychological well-being based on the dimensions of emotional intelligence and achievement motivation

\begin{tabular}{|c|c|c|c|}
\hline & $\boldsymbol{\beta}$ & SE & $\mathbf{b}$ \\
\hline \multicolumn{4}{|c|}{ first step (achievement motivation) } \\
\hline \multirow[t]{4}{*}{ achievement motivation } & $0.278^{* *}$ & 0.234 & 1.223 \\
\hline & \multicolumn{3}{|c|}{$\mathrm{R} 2=0.267$} \\
\hline & \multicolumn{3}{|c|}{$\operatorname{adj} R 2=0.263$} \\
\hline & \multicolumn{3}{|c|}{$676 / 70=(194 ، 1) F$} \\
\hline \multicolumn{4}{|c|}{ second step( emotional intelligence) } \\
\hline self- motivation & 0.027 & 0.824 & 0.296 \\
\hline self-awareness & $0.370^{* *}$ & 0.618 & 3.323 \\
\hline
\end{tabular}




$\begin{array}{llll}\text { self-control } & 0.229 * * & 0.578 & 1.959 \\ \text { Social consciousness } & 0.056 & 0.641 & 0.534 \\ \text { social skills } & -0.003 & 0.652 & -0.030 \\ & \mathrm{R} 2=0.558 & \\ & \Delta \mathrm{R} 2=0.291 & \\ & \operatorname{adjR} 2=0.544 & \\ & 715 / 39=(189 \text { ،6) } \mathrm{F} & \\ \end{array}$

The value of $\underline{\mathrm{R}}^{2}$ reached to 0.558 through entering dimensions of emotional intelligence to the predictive equation of psychological well-being in the second step. This finding means that the dimensions of emotional intelligence with the achievement motivation variable predict generally $55.8 \%$ of psychological well-being variance. Changes value of $\mathrm{R}^{2}\left(\Delta \mathrm{R}^{2}\right)$ was equal to 0.291 and the amount of psychological well-being variance has been increased nearly 29 percent with significant level of $0.01(\mathrm{~F}(189.6)=39.715, \mathrm{p}<0.01)$. The investigation of regression coefficients showed that the regression coefficient of self-awareness $(\beta=0.370, p<0.01)$ and self-control $(\beta=$ $0.229, \mathrm{p}<0.01$ ) can positively predict psychological well-being among other dimensions of emotional intelligence with the significant level of 0.01 . It is said that regression coefficients of other dimensions of emotional intelligence were not significant in level of 0.05 . Therefore, it was concluded that two variables of self-awareness and self-control can positively predict psychological well-being among other dimensions of emotional intelligence with the significant level of 0.01 .

\section{Discussion and Conclusion}

Psychological well-being is not practically separated from development of social and emotional competence, and enjoying emotional intelligence in the process of treatment program is considered as positive steps taken to promote the well-being of people under treatment. Weber believes that well-being is used in a wide range of educational environments, health and social cares. The outcomes of the current research is that today teaching emotional intelligence factors has been gradually common in various training and cultural programs, and it has found its own place in such programs. The research results show that there is a positive and significant correlation between emotional intelligence and psychological well-being. When examining the relationship between emotional intelligence factors and psychological well-being, self-awareness and self-control are the most correlated ones. It means that if these variables increase, the students' psychological well-being will be increased too.

It is said that emotional intelligence can positively predict psychological well-being with the significant level of 0.01. It is consistent with numerous studies conducted in this field and has also been confirmed in studies performed by (Schutte, 1998; Bar-on, 2000; Ciarrocchi, 2004; Austin, 2004; Gannon \& Ranzijn, 2005; Ciarrocchi, Chan, Caputi, \& Roberts, 2001). There is a positive relationship between emotional intelligence and life satisfaction, life quality and social interactions, and a negative relationship between emotional intelligence and loneliness and depression. It can be reported that there is a strong negative relationship between emotional intelligence and depression and hopelessness and a positive relationship between emotional intelligence and emotional health. Regarding the role of emotional intelligence in the modulation of stress and psychological health, there are some evidence suggesting that some aspects of emotional intelligence protect people against stress and lead to better adjustment. For example, there is a relationship between the ability of controlling emotions and tendency to maintain a positive mood and it leads to the prevention of depression. People who are able to control their emotions enjoy more social support and satisfaction and it is possible to protect them against depression and suicide and ultimately it helps improve their psychological well-being (Ciarrocchi, 2004).

On the other hand, research findings showed that there is a significant relationship between achievement motivation and psychological well-being. It is consistent with numerous studies conducted in this field and has also been confirmed in studies performed by (Li, LAN, \& Ju, 2015), (Ramezan Hasanzadeh \& Gelin Mehdinejad, 2012) and (Heta, 2012). The achievement motivation can be considered as the main introduction to the success. It predicts performance outcomes directly (Caldwell, 2005). In general, those who are motivated to be successful are more interested in moving toward the future, and paying attention to innovative activities and they are more involved in future plans. Such people understand the situations in which their abilities are tested (Gjesme, 1981), (Irene Chong, 1997) and (Ahmad, Sulaiman, \& Alias, 2010) has defined the achievement motivation as a 
prerequisite for success and superiority.

\section{Competing Interests Statement}

The authors declare that there is no conflict of interests regarding the publication of this paper.

\section{References}

Ahmad, J., Sulaiman, J., \& Alias, S. (2010). The Effectiveness of Drug Rehabilitation Module on the Motivation Achievement among Male Inmates in Malaysia. International Journal of Psychological Studies, 2, 70-82. https://doi.org/10.5539/ijps.v2n2p70

Austin, E. J., Saklofske, D. H. S., \& Mckenney, D. (2004). Measurment of trait emotional intelligence: testing and cross-validating a modified version of Schutte et al. (1998) measure. Personality and individual differences, 36, 555-562. https://doi.org/10.1016/S0191-8869 (03)00114-4

Bar-On, R. (2000). Emotional and social intelligence: Insights from the Emotional Quotient Inventory (EQ-I). In R. Bar-on \& J. D. A. Parker (Eds), Handbook of Emotional Intelligence. San Francisco: Jossey Bass.

Bar-On, R. (2005). The Bar-On model of emotional-social intelligence. In P. Fernandez Berrical and N. Extreme (guest editors), Special Issue on Emotion Intelligence, Psicothema, 17

Caldwell, L. T. (2005). Considering achievement motives: Exploring educational success in African American students. Doctoral Dissertation, Southern Illinois University Carbondale.

Carmeli, A. (2003). The relationship between Emotional Intelligence and work attitudes, behavior and outcomes, Journal of Managerial Psychology, 18, 788-795. https://doi.org/10.1108/02683940310511881

Cassidy, T., \& Lynn, R. (2009). A multifactorial approach to achievement motivation: The development of a comprehensive measure. Journal of Occupational and Applied Psychology, 72, 301-311.

Ciarrochi, Chan, Caputi \& Roberts (2001). "Measuring Emotional Intelligence”, In C. Ciarrochi, J.P.

Ciarrochi, J, \& West, M. (2004). The relationship between dysfunctional beliefs and positive and negative indices of well-being: A critical evaluation of the Common Beliefs Survey-III. Journal of Rational Emotive and Cognitive Behavior Therapy, 22(3), 171-188. Character, social/emotional well-being. https://doi.org/10.1023/B:JORE.0000047306.55720.4e

Ciarrochi, J., Deanc, F. P., \& Anderson, S. (2002). Emotional intelligence moderates the Relationship between stress and mental Health. Personality and individual differences. https://doi.org/10.1016/S0191-8869 (01)00012-5

Danesh, E., Mohammadi, Sh., Saliminia, A., \& Tankamani, N. (2012). The Relationship between Emotional Intelligence and Irrational Beliefs and Academic Achievement. Scientific - Research Journal of Applied Psychology Research, 3(4), 58-85.

Danner, D., Snowdon, D., \& Friesen, W. (2001). Positive emotion in early life and longevity: Findings from the nun study. Journal of Personality and Social Psychology, 80, 804-813. https://doi.org/10.1037/0022-3514.80.5.804

Diener, E., Suh, E. M., Lucas, R. E., \& Smith, H. L. (1999). Subjective well-being: Three decades of progress. Psychological Bulletin, 125(2), 276-302. https://doi.org/10.1037/0033-2909.125.2.276

Gannon, \& Ranzijn, R. (2005). Does EI predict unique variance in life satisfaction beyond IQ? Personality and individual difference Journal? 35, 300-315.

Gjesme, T. (1981). Is there any future in achievement motivation? Motivation and Emotion, 5, 115-138. https://doi.org/10.1007/BF00993892

Goleman, D. (1995). Emotional intelligence. New York: Bantam. https://books.google.com

Hasanzadeh, R., \& Mehdinejad, G. (2014). The Relationship between Motivational Orientation and Academic Achievement. Journal of School Psychology (JSP), 3(3), 38-60.

Hermans, H. J. M. (1970). A Questionnaire Measure of. Achievement Motivation. Journal of Applied Psychology, 54, 35. https://doi.org/10.1037/h0029675

Irene Chong. (1997). Module Advanced Personal Effectiveness Program on Achievement Motivation in Circles High School Students in Selangor. Project Master sains Yang Tidak Diterbitkan. Serdang: Universiti Putra 
Malaysia. www.ipbl.edu.my/portal/penyelidikan/.../2005/sidekUPM.pdf.

Karimi, Y. (2005). Theories of Personality, (Translated by: Karimi, Y., Jamhari, F., Naghshbandi, S., Gudarzi, B., Bahiraei, H. \& Nikkhu, M.), Tehran: Arasbaran Publications. (Published in Original Language in 1990).

Keyes, C. L. M. (2007). Promoting and protecting mental health as flourishing: acomplementary strategy for improving national mental health. American psychologist, 62, 95-108. https://doi.org/10.1037/0003-066X.62.2.95

Khodayarifard, M., Ghobaribonab, B., Zamanpour, E., Derakhshan, M., Akbarizardkhane, S., \& Al-sadat Musavi, S. (2014). Iranian Positive Thinking Scale (IPTS): Construction and Standardization, Scientific - Research Journal of Applied Psychology Research, 5(4), 103-130.

Li, Y., Lan, L., \& Ju, C. (2015). Personality and Individual Differences, 79(2015), 146-151. https://doi.org/10.1016/j.paid.2015.01.050

Lucas, R. E. Diener, E., \& Larsen, R. J. (2003). Measuring positive emotions. In S. J. Lopez \& C. R. Snyder (Eds), Positive psychological assessment: A handbook of models. https://doi.org/10.1037/10612-013

Mansouri, B. (2001). Standardization of Siberia Schering's Emotional Intelligence Test on Students of Tehran University, Unpublished M.A. Thesis, Allameh Tabataba'i University.

Mavroveli, S., Petrides, K. V., Rieffe, C., \& Bakker, F. (2007). Trait Emotional Intelligence, psychological well-being and peer-rated social competence. Adolescence British journal of developmental psychology, 925, 263-275.

Mayer, J. D., \& Salovey, P. (1997). What is emotional intelligence Educational implications New York? Basic books.

Namdar, K. (2003). Investigating the Comparison between Self-esteem and Motivation for Academic Achievement and its Relationship with Academic Performance of Students with visual and Hearing Impairment, Integrated and Normal Plan Administered in Hamadan in Academic Year of (2003-2004), M.A, Thesis, and Allameh Tabataba'i University.

Olson, L. (2008). Capella University, Emotional intelligence: Conceptualization psychology: Interpersonal process $(\mathrm{N}, 12$. pp. 279-307). London:

Rahiminejad, A., Rahimi Jafari, M., \& Salamati, P. (2015), The Relationship between Identity Styles and Emotional, Social and Psychological Well-being; the Mediating Role of Commitment and Accepting Religious Identity. Scientific - Research Journal of Applied Psychology Research, 6(4), 95-112.

Ryff, C. D. (1985). Adult personality development and the motivation for personal growth. In D. Kleiber \& M. Maehr (Eds.), Advances in motivation and achievement: Motivation and adulthood (Vol. 4, pp. 55-92). Greenwich, CT: JAI Press.

Ryff, C. D. (1995). Psychological well-being in adult life. Current Directions in Psychological Science, 4, 99-104. https://doi.org/10.1111/1467-8721.ep10772395

Schutte, N. S. (1998).Development and validation of a measure of emotional intelligence. Personality and individual differences, 25, 167-177. https://doi.org/10.1016/S0191-8869 (98)00001-4

Settlemyer, B. J. (2010). Achievement motivation profiles of 2010 academic year graduates Newberry College. Doctoral Dissertation, Oklahoma State University.

Shobairi, M. (2014). the Effect of Emotional Intelligence Components on Environmental Behavior of Students. Scientific - Research Journal of Applied Psychology Research, 5(2), p. 132-141.

Tee, S. (2011). The Roles of Emotional Intelligence and Spiritual Intelligence at the workplace. Journal of Human Resources Management Research, 19. Retrieved from http://www.ibimapublishing.com/journals/ JHRMR/jhrmr.html/2011/582992/582992.

Tuominen-Soini, H., \& Salmela-Aro, K. (2012). Schoolwork engagement and burnout among Finnish high school students and young adults: Profiles, progressions, and educational outcomes. Manuscript submitted for publication.

Wessberg, R. P. (2000). Promoting social and emotional competence in children.

Wigfield, A., \& Eccles, J. S. (Eds.). (2002). Development of achievement motivation. San Diego, CA: Academic 
Press.

Yahyazadeh, S. (2005). Investigating the Relationship Emotional Intelligence, Control Source and Psychological Health among Students of Mazandaran University. M.A. Thesis, Teacher Training University.

\section{Copyrights}

Copyright for this article is retained by the author(s), with first publication rights granted to the journal.

This is an open-access article distributed under the terms and conditions of the Creative Commons Attribution license (http://creativecommons.org/licenses/by/4.0/). 